\title{
Análise prospectiva científica e tecnológica sobre Myracrodruon urundeuva (aroeira do sertão) e a resistência bacteriana
}

Scientific and technological prospection study on Myracrodruon urundeuva (aroeira do sertão) and bacterial resistance

Estudio de prospección científica y tecnológica sobre Myracrodruon urundeuva (aroeira do sertão) y resistencia bacteriana

Recebido: 17/08/2021 | Revisado: 22/08/2021 | Aceito: 24/08/2021 | Publicado: 25/08/2021

Davi Santana Sousa
ORCID: https://orcid.org/0000-0001-7103-4441
Universidade Tiradentes, Brasil
Universidad Popular Autónoma del Estado de Puebla, México
E-mail: davi.santana.sousa@ hotmail.com
Giancarlos Costa Rodrigues
ORCID: https://orcid.org/0000-0001-6799-6787
Universidade Tiradentes, Brasil
E-mail: giancarlosfilho@hotmail.com
Lívia Maria do Amorim Costa Gaspar
ORCID: https://orcid.org/0000-0002-4177-5086
Universidade Tiradentes, Brasil
E-mail: amorlivia@gmail.com
Tatiane de Oliveira Xavier Machado
ORCID: https://orcid.org/0000-0002-7363-3752
Universidade Tiradentes, Brasil
E-mail: tatiane.xavier@souunit.com.br
Fernanda Guimaraes Valverde
ORCID: https://orcid.org/0000-0001-9462-5041
Universidade Tiradentes, Brasil
E-mail: valverde_fgv@hotmail.com
Francine Ferreira Padilha
ORCID: https://orcid.org/0000-0002-5892-4252
Universidade Tiradentes, Brasil
E-mail: fpadilha@yahoo.com
Daniela Droppa-Almeida
Universidade Tiradentes, Brasil
E-mail: danieladroppa@gmail.com

\section{Resumo}

As bactérias multirresistentes têm sido uma das maiores causas de infecção e permanência nosocomial. Isso está atribuído a sua capacidade em adquirir resistência a diversos antibióticos, tanto pelo uso incorreto desses medicamentos, como a acomodação ao tratamento proposto. Assim, desta maneira, para essas bactérias, o tratamento convencional com antibióticos não tem o potencial de eliminá-las, sendo assim, diferentes estratégias vêm sendo estudadas, como exemplo a utilização de extratos naturais de plantas medicinais. Diante disso, palavras-chave como: extratos naturais, antibacteriano, Myracrodruon, Myracrodruon urundeuva, Anacardiaceae foram utilizadas para análise prospectiva nos seguintes bancos de dados Science direct, PubMed, SciELO, World Intellectual Property Organization (WIPO) e Instituto Nacional da Propriedade Industrial (INPI). Os resultados permitiram identificar um significativo número de artigos científicos em relação às palavras-chave utilizadas, enfatizando que houve uma diferença no quantitativo apresentado por cada base de dados em decorrência das suas particularidades referente a suas áreas de estudo. Nessa perspectiva, o Science Direct apresentou um maior número de achados em comparação aos demais bancos de dados. Referente à atividade antibacteriana da Myracrodruon urundeuva, o PubMED demonstrou um melhor direcionamento, descrevendo em seus registros a presença de compostos farmacológicos encontrados em extratos da planta que configuram seus efeitos relatados na literatura. Com relação ao depósito de patentes, o INPI por ser nacional, apresentou um quantitativo de patentes menor que o WIPO, em contexto mundial, a China é o país que mais apresentou pedidos de patentes até o momento, seguida da Coreia do Sul e EUA. Os achados remetem a uma carência de investimentos tecnológicos por parte da indústria brasileira. Mesmo diante da baixa aplicabilidade terapêutica da Myracrodruon urundeuva, o Brasil ainda se destaca em relação aos demais países. Seu principal uso refere-se a atividades antiinflamatória, cicatrizante, analgésica e bactericida aplicada à odontologia. A realização da prospecção científica e 
tecnológica é uma ferramenta indispensável para a cadeia produtiva do conhecimento, sendo necessária para um melhor direcionamento da pesquisa.

Palavras-chave: Antibióticos; Bactérias multirresistentes; Extratos naturais; Myracrodruon Urundeuva; Plantas medicinais.

\begin{abstract}
Multiresistant bacteria have been one of the main causes of infection and nosocomial permanence. This is attributed to its ability to acquire resistance to several antibiotics, both through the incorrect use of these drugs and the accommodation to the proposed treatment. Thus, for these bacteria, conventional treatment with antibiotics does not have the potential to eliminate them, so different strategies have been studied, such as the use of natural extracts of medicinal plants. Therefore, keywords such as: natural extracts, antibacterial, Myracrodruon, Myracrodruon urundeuva, Anacardiaceae were used for prospective analysis in the following databases Science direct, PubMed, SciELO, World Intellectual Property Organization (WIPO) and National Institute of Industrial Property (INPI). The results allowed to identify a significant number of scientific articles in relation to the keywords used, emphasizing that there was a difference in the quantity presented by each database due to their particularities regarding their areas of study. From this perspective, Science Direct presented a greater number of findings compared to other databases. Regarding the antibacterial activity of Myracrodruon urundeuva, PubMED demonstrated a better targeting, describing in its records the presence of pharmacological compounds found in plant extracts that configure its effects reported in the literature. With regard to filing patents, the INPI had much lower results in filings than the WIPO, in a global context, China is the country that has filed the most patents so far, followed by South Korea and the USA. The findings point to a lack of technological investments by the Brazilian industry. Even given the low therapeutic applicability of Myracrodruon urundeuva in Brazil, it is still superior to other countries, its main use refers to anti-inflammatory, healing, analgesic and bactericidal activities applied to dentistry. The realization of scientific and technological prospecting is an indispensable tool for the knowledge production chain, being necessary for a better direction of research.
\end{abstract}

Keywords: Antibiotics; Multi-resistant bacteria; Natural extracts; Myracrodruon Urundeuva; Medicinal plants.

\title{
Resumen
}

Las bacterias multirresistentes han sido una de las principales causas de infección y permanencia nosocomial. Esto se atribuye a su capacidad para adquirir resistencia a varios antibióticos, tanto por el uso incorrecto de estos fármacos como por la acomodación al tratamiento propuesto. Así, para estas bacterias, el tratamiento convencional con antibióticos no tiene potencial para eliminarlas, por lo que se han estudiado diferentes estrategias, como el uso de extractos naturales de plantas medicinales. Por tanto, se utilizaron palabras clave como: extractos naturales, antibacteriano, Myracrodruon, Myracrodruon urundeuva, Anacardiaceae para el análisis prospectivo en las siguientes bases de datos Science direct, PubMed, SciELO, Organización Mundial de la Propiedad Intelectual (OMPI) e Instituto Nacional de Propiedad Industrial (INPI). Los resultados permitieron identificar un número significativo de artículos científicos en relación a las palabras clave utilizadas, destacando que hubo diferencia en la cantidad presentada por cada base de datos debido a sus particularidades con respecto a sus áreas de estudio. Desde esta perspectiva, Science Direct presentó un mayor número de hallazgos en comparación con otras bases de datos. En cuanto a la actividad antibacteriana de Myracrodruon urundeuva, PubMED demostró una mejor focalización, describiendo en sus registros la presencia de compuestos farmacológicos encontrados en extractos de plantas que configuran sus efectos reportados en la literatura. En cuanto a la presentación de patentes, el INPI tuvo resultados mucho más bajos en presentaciones que la OMPI, en un contexto global, China es el país que ha presentado más solicitudes de patente hasta el momento, seguido de Corea del Sur y Estados Unidos. Los hallazgos apuntan a una falta de inversiones tecnológicas por parte de la industria brasileña. Incluso dada la baja aplicabilidad terapéutica de Myracrodruon urundeuva en Brasil, sigue siendo superior a otros países, su uso principal se refiere a actividades antiinflamatorias, cicatrizantes, analgésicas y bactericidas aplicadas a la odontología. La realización de la prospección científica y tecnológica es una herramienta indispensable para la cadena de producción del conocimiento, siendo necesaria para una mejor dirección de la investigación.

Palabras clave: Antibióticos; Bacterias multirresistentes; Extractos naturales; Myracrodruon Urundeuva; Plantas medicinales.

\section{Introdução}

A utilização de plantas fitoterápicas tem aumentado por todo o mundo, bem como no Brasil, uma vez que já é possível observar na literatura que a produção e o consumo de fitoterápicos aumenta substancialmente, o que pode ser observado de forma quantitativa com o aumento de aproximadamente 7\% em 2014 e $8 \%$ em 2015, de acordo com o estudo de Hasencleveret et al, (2017). Além disso, segundo Firpo (2015), a pesquisa de novas moléculas é o objetivo da maioria das indústrias farmacêuticas 
e dos grandes centros de pesquisas localizados nos Estados Unidos e Europa, sendo mais viável estudar as moléculas naturais do que planejar novos fármacos ao acaso. Diante disso, o uso de plantas medicinais vem sendo utilizado para produção de óleos essenciais e extratos naturais, os quais possuem compostos bioativos com diversas propriedades terapêuticas já relatados amplamente na literatura (Batista et al., 2020, Ce et al., 2017, da Silva \& Aquino, 2018, Sousa \& Silveira, 2018), De Amaral et al., s.d.).

Ao se falar especificamente sobre extrato natural, trata-se de um produto proveniente da extração com uso de solventes diversos, sendo esse produto líquido, viscoso ou sólido. Os constituintes solúveis em água (hidrofílicos) podem ser extraídos com água, enquanto os constituintes solúveis em gordura (lipofílicos) são extraídos de uma parte específica da planta com álcool ou outros solventes; estas podem ser obtidas de diferentes partes da planta, como: casca, folha, talo, chips, sementes ou lenho. O uso de extratos obtidos através de plantas tem sido adotado na medicina pela ampla presença de metabólitos secundários que, contribuem com a adaptabilidade da planta, porém pode apresentar diversas atividades terapêuticas, como exemplo, tais compostos podem interagir com alvos importantes de certos patógenos e atuar como potencial antimicrobiano, e a presença desses compostos em sinergismo pode inclusive impossibilitar o aparecimento de mecanismos de resistência servindo como uma potencial estratégia frente a esses microrganismos multirresistentes (Domingos \& Silva, 2020, Filipini, \& Silva, 2019, Goes et al. 2020, GS et al., 2003, Hasenclever et al., 2017).

Quando se fala de resistência bacteriana, entende-se como um fenômeno natural, no qual há capacidade das bactérias de resistirem à ação de antibióticos. Isso acontece quando as bactérias passam por mutações e adquirem essa habilidade. Com isso, as opções de tratamentos tradicionais se tornam ineficazes, acarretando infecções persistentes com alto potencial de transmissibilidade, levando, destarte, a impactos de dimensões sociais, econômicas e ambientais, uma vez que a resistência eleva custos de tratamentos, prolonga a permanência de pacientes em hospitais e contribui para o aumento dos índices de mortalidade (Indicadores, s.d.). Entre as notáveis bactérias que mais apresentam resistência aos antimicrobianos estão Escherichia coli, Klebsiella pneumoniae, Staphylococcus aureus, Neisseria gonorrhoeae, Chlamydia trachomatis e Treponema pallidum.

Em razão disso, a indústria farmacêutica busca, incessantemente, por substâncias capazes de agirem contra a multirresistência desenvolvida pelos patógenos e ao mesmo tempo que sejam de origem natural com pouca ou nenhuma nocividade para o organismo e de baixo custo. Neste contexto, o Brasil torna-se um local de grande importância devido a sua biodiversidade e, uma das espécies presentes no Cerrado brasileiro com muitas atividades farmacológicas já relatadas na medicina popular é a Myracrodruon urundeuva (Aroeira do sertão). Descrita por Freire Allemão em 1862, esta espécie tem apresentado potencial antimicrobiano, o qual foi evidenciado quando o uso de seu extrato bruto foi capaz de apresentar-se antibacteriana frente a Staphylococcus aureus, Staphylococcus epidermidis, Escherichia coli, Pseudomonas aeruginosa e Salmonella Enteritidis e antifúngica, frente a Candida albicans, Candida tropicalis e Candida krusei (Domingos \& Silva, 2020).

Além disso, outros estudos indicam propriedades antiparasitárias (Carvalho et al., 2017), analgésicas e antiinflamatórias (Viana et al., 2003) incentivando a pesquisa sobre os possíveis usos dessa planta medicinal como possível fitoterápico. Ademais, aliados aos baixos níveis de toxidade, os extratos naturais surgem como uma estratégia médica capaz de contribuir de modo significativo com a regressão de agravos à saúde de maneira objetiva, com baixo custo-benefício e menores efeitos colaterais. Diante disso, este estudo tem por objetivo realizar um mapeamento prospectivo a respeito do avanço tecnológico e científico de forma sistematizada a respeito dos extratos naturais e seus possíveis potenciais antibacteriano, destacando o uso da M. urundeuva.

\section{Metodologia}

\subsection{Prospecção Científica}

Para realizar a Prospecção Científica, foram executadas buscas em três bancos de dados, com o objetivo de procurar 
documentos apropriados que correspondam aos objetivos deste estudo. As bases de dados selecionadas foram: The National Library of Medicine (MEDLINE/PubMed), Science Direct, e Scientific Electronic Library Online (SciELO). Essa pesquisa ocorreu para que pudesse encontrar artigos que tratem a respeito das plantas medicinais que possuam potenciais antimicrobianos.

Foram incluídos os artigos a partir da combinação das seguintes palavras-chave: < extratos naturais >, < extratos naturais AND antibacteriano >, $\langle$ Myracrodruon $\rangle$, $\langle$ Myracrodruon AND antibacteriano $\rangle$; $\langle$ Myracrodruon urundeuva $\rangle$, < Myracrodruon urundeuva AND antibacteriano $>$, $\langle$ Anacardiaceae $\rangle$ e $<$ Anacardiaceae AND antibacteriano $>$, e termos de pesquisa e operadores booleanos (< palavra-chave $1>$ [Termos MeSH] AND < palavra-chave $2>$ ) para todas as buscas e combinações estabelecidas com base nas palavras-chave já descritas. A busca foi realizada selecionando artigos dos últimos 10 anos, nos idiomas inglês, português e espanhol.

\subsection{Prospecção Tecnológica}

Com os resultados da prospecção científica obtidos, foi realizada uma prospecção tecnológica para verificar patentes existentes tanto sobre extratos naturais relacionados a potenciais antimicrobianos quanto sobre uso dos extratos naturais de maneira geral. Para isso, foram usados os depositórios PatentScope, presente na Organização Mundial de Propriedade Intelectual (The World Intellectual Property Organization (WIPO)) e o INPI (Instituto Nacional da Propriedade Industrial). Para a determinação do código internacional, foi utilizado a base de International Patent Classification (IPC) que é de acesso livre usualmente selecionada para prospecções tecnológicas. No intuito de verificar a diferença entre o uso de código e o uso de < palavras-chave >, as mesmas palavras-chaves da prospeç̧ão científica foram utilizadas no PatentScope em inglês, e em português para as buscas no Instituto Nacional da Propriedade Industrial (INPI).

A estratégia da pesquisa visou garantir que a maior parte das patentes fossem localizadas e processadas. Assim, foi adotada uma estratégia semelhante à definida por Quintella et al. (2009) utilizando os termos selecionados presentes no resumo ou no título. Com o intuito de fazer uma comparação entre publicação de artigos de maneira geral com a propriedade intelectual, as mesmas palavras-chave também foram utilizadas no Sciencedirect.

\section{Resultados}

\subsection{Prospecção Científica}

Sabe-se que a utilização de espécies vegetais para fins terapêuticos é uma prática medicinal conhecida na humanidade desde a antiguidade e sendo muito utilizada ao redor do mundo até os dias atuais (Caetano et al., 2015). Nos últimos anos, vários pesquisadores desenvolveram estudos sobre a atividade biológica de plantas medicinais orientados em sua maioria pelo uso popular para o tratamento de diversas enfermidades (Zago, 2018). Dentre as principais enfermidades em crescimento, estão aquelas causadas por microrganismos, uma vez que os mesmos possuem uma alta resistência aos fármacos que são disponibilizados pela indústria atual. Entre esses microrganismos as bactérias destacam-se devido a busca recorrente por novos antibióticos. A partir disso, diante das buscas foi possível verificar uma discrepância entre as palavras-chaves utilizadas, e na Figura 1 é possível encontrar os resultados totais obtidos utilizando <extratos naturais> e <antibacteriano AND extratos naturais>, indicando a tentativa em mitigar os problemas atuais existentes em relação as bactérias multirresistentes. 
Figura 1. Resultados encontrados no PubMED, Science Direct e SciELO com as palavras-chaves <extratos naturais> e <antibacteriano AND extratos naturais>.

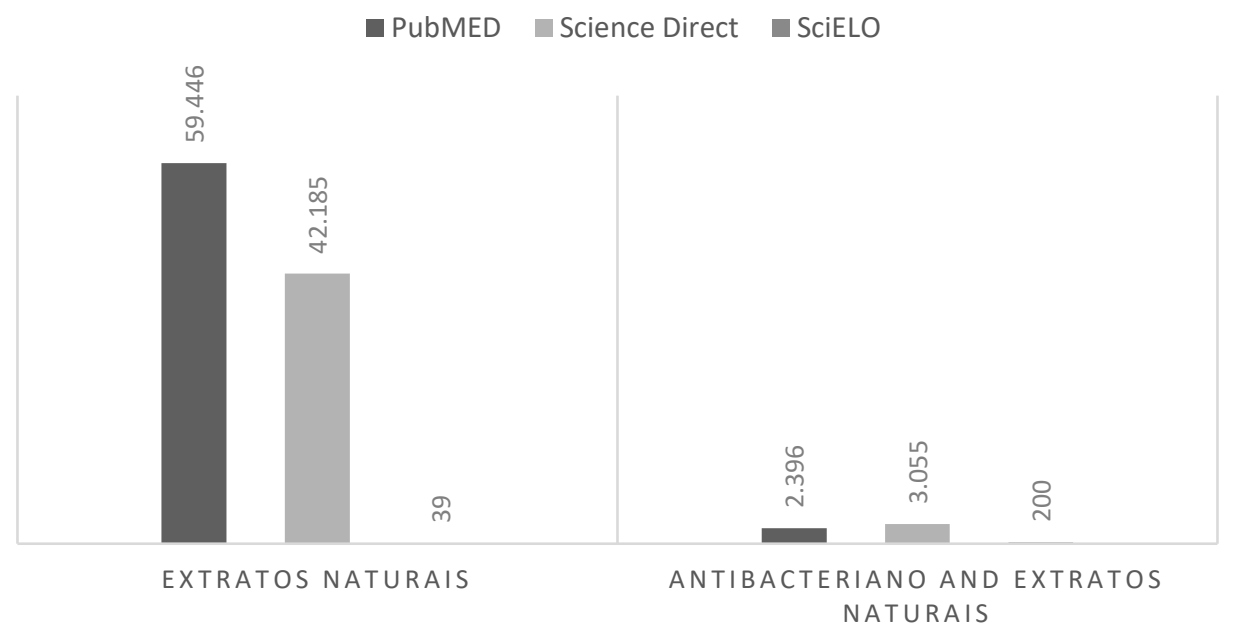

Fonte: Autores.

Ao verificar a busca na utilização de extratos naturais como potencial antibacteriano foi possível verificar diversas plantas medicinais utilizadas, como:

Ao se verificar as plantas mais utilizadas podemos destacar os países tropicais devido ao clima e biodiversidade servindo como fonte de matéria-prima importante para a busca de novos compostos e novos fármacos. No Quadro 1 é possível verificar os resultados obtidos com todas as palavras-chaves utilizadas nesse estudo.

Quadro 1. Resultados obtidos a partir da busca pelas palavras-chaves nas bases de dados científicas.

\begin{tabular}{|l|c|c|c|}
\hline Palavras-Chaves & SciELO & PubMED & Science Direct \\
\hline Anacardiaceae & 318 & 4163 & 5380 \\
\hline Myracrodruon & 129 & 71 & 236 \\
\hline Myracrodruon Urudueva & 127 & 69 & 232 \\
\hline < Antibacteriano > AND < Anacardiaceae > & 8 & 282 & 940 \\
\hline < Antibacteriano > AND < Myracrodruon urundeuva > & 0 & 10 & 47 \\
\hline
\end{tabular}

Fonte: Autores.

Conforme a Tabela 1, pode-se perceber que há diferenças em relação ao número de artigos pesquisados nas bases de dados estudadas, o que já é um resultado esperado, visto que são bibliotecas diferentes. Por exemplo, o SciELO é uma biblioteca de livre acesso voltado para revistas da América latina e outros países como África do Sul, Espanha e Portugal. Já o PubMED é uma biblioteca dos Estados Unidos da América (EUA) voltada para a área da saúde que além de indexar aproximadamente 5 mil revistas nos EUA indexa de mais de 80 países, apresentando um percentual de artigos na área da saúde muito superior ao SciELO. O Science Direct por sua vez é uma biblioteca anglo-holandesa da editora Elsevier e apesar de indexar um menor quantitativo de revistas ao se comparar com o PubMED, esta biblioteca não inclui apenas temas voltados a saúde e sim a diversas áreas, como química, alimentícia, industrial, etc. Diante desse conhecimento é compreensível verificar essa diferença de artigos entre as bibliotecas utilizadas, porém o uso da palavra-chave $<$ Anacardiaceae $>$ nos revelam que apesar da grande quantidade de plantas presentes em países tropicais, inclusive desse gênero, a maior quantidade desses artigos é publicada em revistas estrangeiras e com isso, indexadas por bibliotecas como PubMED e o Science Direct. 
A família Anacardiaceae está presente principalmente em ambientes secos e úmidos, preferencialmente em regiões tropicais e subtropicais, podendo também estar presente em climas temperados. Nessa família estão presentes cerca de 81 gêneros e 800 espécies, destes 32 gêneros são nativos do continente Americano e aproximadamente 25 são endêmicos. No Brasil 14 são gêneros são catalogados com um total de 57 espécies, destas espécies 14 são endêmicas. Essa família possui uma importância econômica gigantesca devido a quantidade de frutos comestíveis, madeiras ou espécies ornamentais advindos da mesma. Já ao se comparar os achados relativos ao gênero <Myracrodruon> e a espécie <Myracrodruon urundeuva $>$ foi encontrado um quantitativo superior de artigos na SciELO em relação ao PubMED o que nos mostra que a biodiversidade presente na América latina tem sido uma das estratégias encontradas nessa região para busca de novos compostos, independente da sua propriedade farmacológica. No entanto, ao se comparar ambas palavras-chaves com os achados do Science Direct o quantitativo é quase que o dobro, e a isto deve-se a repetição de artigos entre as bases do PubMED e a do Science Direct e devido as diversas revistas em áreas diversas que o Science Direct indexa. Muitos artigos encontrados no Science Direct com ambas palavras-chaves eram relativos as análises químicas, filogenéticas e em relação a morfologia vegetal do gênero e da M. urundeuva. Vale ressaltar os achados acerca do uso das palavras-chaves $<$ Myracrodruon $>$ e $<$ Myracrodruon urundeuva $>$ no PubMED e no Science Direct que indicam que dentre as espécies pertencentes a esse gênero a $M$. urundeuva possui grande destaque, onde dos 71 artigos abordando este gênero 69 eram relativos a M. urundeuva no PubMED e o mesmo pode ser observado no Science Direct com um total de 236 e 232 para as palavras-chaves $<$ Myracrodruon $>$ e $<$ Myracrodruon urundeuva $>$ respectivamente.

$\mathrm{Na}$ Tabela 1 também é possível verificar as palavras-chaves associadas como < Antibacteriano > AND < Anacardiaceae $>\mathrm{e}<$ Antibacteriano $>$ AND $<$ Myracrodruon urundeuva $>$ mostrando apenas artigos relativos a primeira combinação para o SciELO, e um total de 282 e 10 achados no PubMED e 940 e 47 para o Science Direct, respectivamente. Ao associar a palavra-chave <antibacteriano> com o < Myracrodruon urundeuva > observa-se que apenas 14\% (PubMED) e 20\% (Science Direct) dos artigos relativos a espécie M. urundeuva são voltados para atividade antibacteriana, no entanto, isso indica a importância dessa espécie e suas diversas atividades farmacológicas relatadas na literatura, como: antiparasitárias, analgésicas, anti-inflamatórias, antioxidante, antimineralizadora, antifúngica, ovicida, gastroprotetora, cicatrizantes entre outras.

Diante das buscas realizadas acima, foi possível perceber que os achados entre as três bibliotecas que pode refletir melhor o cenário atual e a temática desses estudos foi o do PubMED, totalizando 10 artigos que relatam o potencial antimicrobiano da Myracrodruon urundeuva, a qual é conhecida popularmente como "aroeira-do-sertão" e tem sido usada em diversos problemas ginecológicos, como um extrato aquoso preparado a partir da casca do caule da planta. Nativa da América do Sul e é encontrada em regiões de clima tropical e subtropical, na região Nordeste do Brasil (Carvalho et al., 2017). No Brasil essa planta apresenta muita importância para região Nordeste e destes 10 artigos encontrados na PubMED todos são de pesquisas oriundas do Brasil e seis são da Universidade do Ceará. Nestes achados, foi possível verificar que parte do potencial antibacteriano dessa planta é devido a presença de lectinas que apresentou atividade antibacteriana contra isolados clínicos não resistentes e resistentes de S. aureus e efeitos sinérgicos com antibióticos na redução do crescimento e formação de biofilme (Júnior et al., 2020). O óleo essencial de suas folhas também foi avaliado e segundo Araújo et al., (2017) apresentou teores de $\alpha$-pineno, trans-cariofileno, limoneno e $\beta$-pineno e isso contribui para sua atividade antibacteriana frente a $S$. aureus, Staphylococcus epidermidis, Escherichia coli, Pseudomonas aeruginosa e Salmonella enteritidis. Em outro estudo de Fernandes (2011), verificou o potencial antibacteriano de extratos etanólico pelo método de disco difusão contra E. coli ATCC 25922, Pseudomonas aeruginosa ATCC 27853 e Staphylococcus aureus ATCC 25923 e foi verificado a presença de halos de inibição de crescimento bacteriano frente as S. aureus ATCC 25923 e P. aeruginosa ATCC 27853. Entretanto o extrato avaliado por Fernandes (2011) não apresentou atividade para a cepa E. coli ATCC 25922. Em outro estudo utilizando extratos Cardoso (2009) revelou que o extrato aquoso das folhas de $M$. urundeuva apresentou atividade na concentração de 1,0; 2,0 e 3,0 mg/disco frente às linhagens de Klebsiella pneumoniae ATCC 70603, Salmonella cholerea-suis ATCC 10708, S. aureus ATCC 6538, S. aureus 
SAIACLIN (S. aureus Isolado de Amostra Clínica), P. aeruginosa ATCC 15442. No entanto, para o Micrococcus luteus ATCC 9341 a concentração de $1,0 \mathrm{mg} /$ disco não apresentou atividade.

\subsection{Prospecção Tecnológica}

Em relação às buscas nos repositórios de patentes (Quadro 2), foi possível verificar que o INPI apresenta um número muito reduzido de patentes solicitadas e registradas quanto às variáveis apresentadas nesse estudo, isso pode ser justificado pelo expoente de investimento em relação ao desenvolvimento, tecnologia e inovação, variáveis que podem ser aplicadas diretamente ao Produto Interno Bruto (PIB). Uma vez que no Brasil, foi observado nos últimos cinquenta anos uma grande evolução econômica coordenada pelas indústrias, que gradativamente desvalorizaram o setor primário e o seu crescimento. Esse ocorrido, fortaleceu a expansão de empresas estrangeiras no país, que vem criando base desde o ano de 1950. Nessa analogia, mesmo com todo investimento, crescimento e incentivo no Brasil a comercialização internacional, nos últimos tempos, ainda é predominantemente de produtos primários, como por exemplo, a soja, que rendeu US\$ 7 bilhões anuais, em comparação a venda de semicondutores produzidos na Coreia do Sul, já ultrapassou os US\$ 30 bilhões anuais. A contar também que a porcentagem do PIB direcionada para P\&D e atividades científicas e técnicas correlatas no Brasil é ainda irrisório a comparar com demais países que se destacam em relação a invenções, mesmo que nos últimos anos estudos tenham apontado um crescimento, quando se foi implementado formas de investimento como, a Lei de Inovação e a Lei do Bem. Em 2009 o percentual chegou a 1,24\%, enquanto a nível de comparação na Coreia era de 3,37\% no ano de 2008, nos Estados Unidos no mesmo período chegou a 2,77\% de investimento do PIB na área (Bezerra, 2019).

Quadro 2. Resultados obtidos a partir da busca pelas palavras-chaves nas bases de dados tecnológicas.

\begin{tabular}{|l|c|c|}
\hline Palavra-Chave & INPI & WIPO \\
\hline Extratos Naturais & 129 & 135828 \\
\hline Myracrodruon & 6 & 3 \\
\hline Myracrodruon urudueva & 6 & 3 \\
\hline Anacardiaceae & 4 & 2190 \\
\hline < Antibacteriano > AND < extratos naturais > & 1 & 64967 \\
\hline < Antibacteriano > AND < Anacardiaceae > & 0 & 1350 \\
\hline < Antibacteriano > AND < Myracrodruon urundeuva > & 0 & 3 \\
\hline
\end{tabular}

Fonte: Autores.

O que reforça a ausência de investimento ou até a demora do processo de patentes no Brasil é quando se compara o quantitativo de patentes com as palavras-chaves 〈extratos naturais〉, 〈Anacardiaceae〉, assim como com as associações no INPI e no WIPO, em que a discrepância no quantitativo de invenções é gigantesco. Porém quando se trata da <Myracrodruon $>$ e $<$ Myracrodruon urundeuva > verifica-se que o INPI possui invenções a mais, seja com o gênero ou com a espécie. E isso está atribuído ao gênero ser endêmico do continente Americano e a própria importância que a aroeira, no caso a espécie, possui no Brasil como foi dito anteriormente.

Os achados tecnológicos dessa prospecção refletem o cenário atual onde a busca por novos compostos bioativos com diversas propriedades é constante e isso é perceptível pelo quantitativo encontrado quando a palavra-chave <extratos naturais> foi utilizada isoladamente no WIPO. Para compreender melhor as diversas aplicações encontradas nessas invenções foi realizada a correlação com os IPCs e dentres estes, 70\% das invenções eram relativas ao A61K o qual está relacionado com invenções contendo: "Preparações para finalidades médicas, odontológicas ou higiênicas"; 35,2\% estavam relacionadas com o A61Q que 
está relacionado com "Uso específico de cosméticos ou preparações similares para higiene pessoal"; 34,5\% com o IPC A61P que envolve invenções cuja a finalidade é "Atividade terapêutica específica de compostos químicos ou preparações medicinais", outros códigos também estiveram presentes como o A23L, A23V, A01N, C12N, dentre outros.

A mesma correlação foi feita com a <Anacardiaceae > e indicou um perfil diferente em que 45,7\% das invenções foram relacionadas com o IPC A01N que relaciona invenções contendo "Preservação de corpos de humanos ou de animais ou de plantas ou de partes dos mesmos (conservação de alimentos ou gêneros alimentícios A23); enquanto que 25,3\% das patentes estavam relacionadas com o IPC C07D relacionados com os compostos presentes, ou seja, caracterizações químicas de compostos e seus processos "Compostos heterocíclicos"; com 23 e 18\% respectivamente apareceram os IPCs A61K e A61P amplamente encontrados na palavra-chave <extratos naturais>; com 16\% o IPC C12N apareceu relacionando a família Anacardiaceae com invenções contendo "Microrganismos ou enzimas; composições das mesmas; propagando, preservando ou mantendo microrganismos; mutação ou engenharia genética; meios de cultura". Com o IPC C12N invenções voltadas a modificações de plantas ou partes das plantas como forma de fornecer melhorias as mesmas são amplamente vistas dentre os achados.

Vale ressaltar que dentre as diversas vantagens que são oferecidas pela criação de patentes, pode-se citar, os incentivos ao desenvolvimento tecnológico, bem como o encorajamento à pesquisa científica, à disseminação do conhecimento prático e econômico, à criação de novos mercados e à satisfação das necessidades latentes dos consumidores (Fernandes, 2019). Ademais, a partir da análise das informações referentes aos dados de investigação tecnológica contidas na Tabela 2, é possível encontrar subsídios para afirmar o grande potencial de novas descobertas acerca do uso do extrato natural da Myracrodruon frente à resistência bacteriana, uma vez que a mesma possui embasamento científico para sua formulação, não obstante ainda não possui nenhuma propriedade tecnológica oferecida para o início da sua produção e distribuição para uso coletivo.

Embora muitas indústrias farmacêuticas tenham produzido novos antibióticos e modificado alguns fármacos já existentes, o consumo excessivo de antibacterianos em alguns países, têm resultado no aumento de resistência bacteriana, causando sério problema de saúde pública (Santos et al., 2007; Duarte, 2006). Por outro lado, os medicamentos fitoterápicos estão sendo empregados como alternativas no tratamento contra diferentes patógenos. A partir dos extratos e óleos essenciais das plantas, são obtidos compostos que, apesar de conter estruturas químicas diferenciadas dos antimicrobianos produzidos a partir de bactérias e fungos, têm demonstrado eficiência no controle do crescimento de uma ampla variedade de microrganismos. Em sua maioria, os constituintes químicos responsáveis pela atividade farmacológica não são conhecidos, mas acredita-se que envolva a interação de inúmeras moléculas presentes no extrato (Yunes \& Calixto, 2001). Dados sobre a atividade antibacteriana de extratos vegetais frente a variados microrganismos permitem evidenciar que as plantas apresentam potencial para o tratamento terapêutico, apesar de muitos destes extratos não terem sido completamente investigados cientificamente (Nascimento et al., 2000). Com base nisso, pode-se observar que os crescentes usos de extratos naturais para essa finalidade dão margem para o considerável achado relacionado a combinação das palavras-chaves < Antibacteriano > AND < extratos naturais> (Tabela 2), outra importante correlação é tentar compreender quais países estão sendo os responsáveis no desenvolvimento dessas tecnologias utilizando extratos naturais como potencial antibacteriano. Na Figura 2 é possível verificar os principais países detentores dessas tecnologias. Nesse sentido, observou-se que a China teve o maior número de registros solicitados, seguida da Coreia do Sul e Estados Unidos, entrando em contraposição com o México, uma vez que o mesmo solicitou o menor número de registros dentre os achados no WIPO. 
Figura 2. Resultados obtidos a partir da combinação das palavras-chaves < Antibacteriano > AND < extratos naturais > em relação ao país de depósito das referidas patentes.

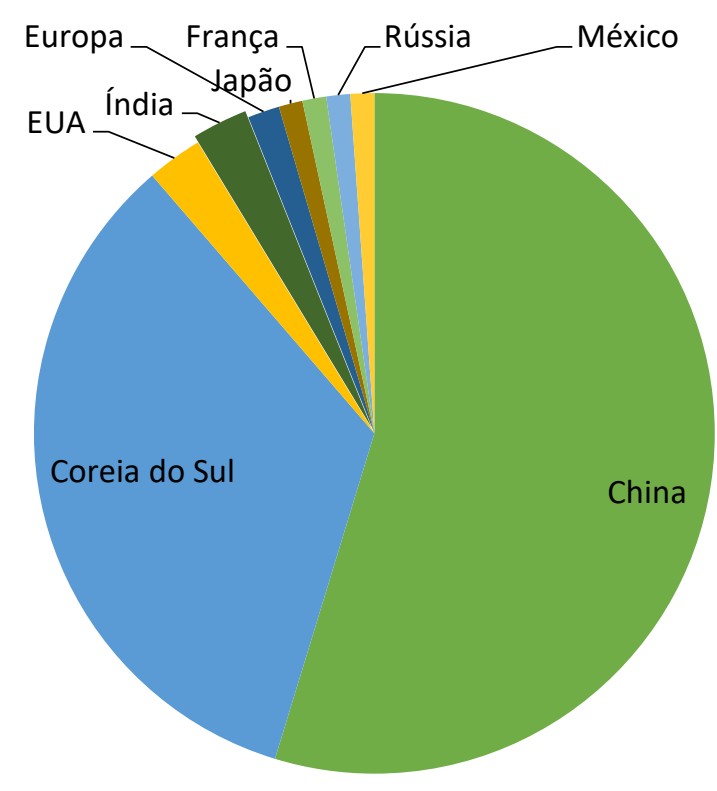

Fonte: WIPO - World Intellectual Property Organization.

Em 2013, durante a Conferência Internacional sobre Medicina Tradicional (MT) dos países da Ásia Sul oriental foi declarado que: "a medicina tradicional de qualidade, segura e com eficácia comprovada contribui para assegurar o acesso de todas as pessoas à atenção primária de saúde. Para milhões de pessoas, as plantas, os tratamentos tradicionais e as práticas da medicina tradicional representam a principal fonte de atenção à saúde e às vezes a única” (OMS, 2013). O alavanque ocasionado pela Conferência em 2013 pode ser um fator predisponente ao aumento significativo da produção e registro de patentes a partir do ano seguinte ao evento (2014), bem como, pode justificar o aumento da produção em relação aos países asiáticos, como China e Coreia do Sul, que lideram a produção mundial (Figura 2).

Além disso, a busca de registros e instrumentos de propriedade intelectual de forma mundial atingiu um nível histórico em 2017, com a China liderando os pedidos de patente, de marca e de desenho ou modelo industrial e outros direitos de propriedade intelectual (PI) que se encontram no centro da economia global. Inovadores em todo o mundo depositaram 3,17 milhões de pedidos de patente, apresentando mais que 5,8\% de aumento consecutivo, segundo o relatório anual da OMPI que está relacionado aos Indicadores mundiais relativos à propriedade intelectual (IMPI). A atividade global de depósito de pedidos de marca atingiu 12,39 milhões, enquanto o número de pedidos de desenho ou modelo industrial foi de 1,24 milhões. A China concedeu o maior volume de pedidos para cada um destes direitos de PI.

Mundialmente, os pedidos de proteção de variedades vegetais aumentaram de 11,7\% para atingirem 18.490 pedidos em 2017, enquanto dados fornecidos por 82 autoridades nacionais e regionais mostram a existência de cerca de 59.500 indicações geográficas protegidas em 2017 (OMPI, 2018). O Instituto de propriedade intelectual da China recebeu o número mais elevado de pedidos de patente em 2017, um recorde de 1,38 milhões. Em 2017, a China redefiniu o seu método de compilação de estatísticas relativas a pedidos de patente e de desenho ou modelo industrial, de maneira a contar apenas os pedidos para os quais foram pagas as taxas de depósito. A seguir ao Instituto de PI da China, vêm o Instituto dos Estados Unidos da América, do Japão, da República da Coreia, e o Instituto Europeu de Patentes. A Ásia fortaleceu a sua posição de região com a maior atividade relativa a depósitos de pedidos de patente. Os Institutos situados na Ásia receberam $65,1 \%$ de todos os pedidos depositados em 
todo o mundo em 2017 - um aumento considerável do nível de 2007, isto é 49,7\% — impulsionado sobretudo pelo crescimento da China. O que também justifica o número de patentes registradas na China e na Coreia do Sul.

Neste cenário, o Brasil se encontra bem distante dessa realidade mencionada acima, no entanto, devido a sua biodiversidade e um quantitativo enorme de plantas endêmicas com potencial terapêutico com destaque a $M$. urundeuva e seu potencial amplamente descrito na literatura foi possível encontrar seis patentes no INPI que estão descritas no Quadro 3.

Quadro 3. Patentes obtidas a partir da busca da palavra-chave $<$ Myracrodruon Urundueva $>$ na base de dados brasileira Instituto Nacional de Propriedade Industrial (INPI).

\begin{tabular}{|l|l|}
\hline CIP/IPC & TíTULO DA PATENTE \\
\hline $\mathbf{A 6 1 K ~ 3 6 / 1 8 5}$ & Composição para o tratamento de Candidíase \\
\hline $\mathbf{A 6 1 K ~ 3 6 / 2 2}$ & $\begin{array}{l}\text { Composição sinérgica multiativa para tratamento tópico de afecções em mamíferos, uso de } \\
\text { composição e método }\end{array}$ \\
\hline $\mathbf{A 6 1 K ~ 3 6 / 2 2}$ & $\begin{array}{l}\text { Processo para obtenção de extratos hidroalcoólicos obtidos a partir da casca da Myracrodruon } \\
\text { urundeuva como atividade anti-inflamatória, cicatrizante e analgésica e atividade anti- } \\
\text { inflamatória e bactericida em desordens periodontais e produto obtido }\end{array}$ \\
\hline $\mathbf{A 6 1 K ~ 3 6 / 2 2}$ & $\begin{array}{l}\text { Uso de composição farmacêutica contendo extrato etanólico padronizado das folhas de } \\
\text { Myracrodruon urundeuva e uso }\end{array}$ \\
\hline A61K 8/73 & $\begin{array}{l}\text { Combinação de uso de exopolissacarídeos microbianos e ácidos urônicos com plantas, ervas } \\
\text { e extratos vegetais na obtenção de produtos cosméticos e dermatológicos }\end{array}$ \\
\hline A61K 31/121 & $\begin{array}{l}\text { Chalconas diméricas em extrato hidroalcoólico obtidas de renovos de Myracrodruon } \\
\text { urundeuva fr. All }\end{array}$ \\
\hline
\end{tabular}

Fonte: INPI - Instituto Nacional da Propriedade Industrial.

A partir da Tabela 3, pode-se observar que a exploração e aplicação da M. urundeuva no Brasil apesar de baixa, apresenta uso principalmente para atividade anti-inflamatória, cicatrizante, analgésica, bactericida quando relacionada a ações odontológicas. Sendo que algumas composições farmacêuticas já foram elaboradas, patenteadas e distribuídas, levando a acreditar nos reais benefícios e potenciais dessa planta medicinal. Outrossim, o último depósito brasileiro referente a essa planta foi no ano de 2012, indicando que ainda se trata de uma planta pouco explorada e entendida, bem como, abre espaço para que novas investigações a respeito de potenciais já descritos na literatura sejam potencializadas, gerando produções tecnológicas que deem origem a novos registros e novas produções comerciais.

\section{Conclusão e Considerações Finais}

Com base nos resultados aqui expostos, podemos concluir que há muitos artigos científicos referentes ao uso de extratos naturais para atividade antibacteriana, porém, notamos uma significativa discrepância entre os bancos de dados, destacando o Science Direct com um maior número de achados, por se tratar de uma base que engloba temas voltados a diversas áreas, como química, alimentícia, industrial, etc, e não apenas restrita a área da saúde. Porém, no que se refere ao uso da Myracrodruon urundeuva da família Anacardieaceae, o PubMED mostrou-se a base de dados com maior direcionamento em estudos voltados ao seu potencial antibacteriano, em um total de 10 artigos, ambos de origem brasileira assim como a espécie. Parte da atividade antibacteriana relatada, se dá pela presença de Lectinas e compostos bioativos presentes em extratos da planta, tais como $\alpha$ pineno, trans-cariofileno, limoneno e $\beta$-pineno.

Por outro lado, notamos em relação ao quantitativo de patentes depositadas por cada país, que a China apresenta dominância em relação ao número de pedidos referentes ao uso tecnológico de extratos naturais para atividade antibacteriana, seguido pela Coréia do Sul e Estados Unidos. Apesar da sua extensa biodiversidade vegetal, o Brasil por sua vez, não apresenta um número significativo de pedidos, tendo aplicações patenteadas principalmente na odontologia em atividade anti-inflamatória, cicatrizante, analgésica, bactericida.

Nossos achados reforçam a necessidade de investimentos tecnológicos por parte da indústria brasileira, ressaltando que 
os extratos naturais de plantas são opções bem ascendentes por se tratar de uma medida terapêutica com um custo reduzido e com uma acessibilidade expoente, sendo, destarte, uma opção com baixo teor de toxidade para o ser humano quando contraposto com as demais terapias normalmente apresentadas e optadas na atualidade. Constata-se com base nesse estudo prospectivo que há poucas patentes relacionadas diretamente ao uso de extratos naturais frente a resistência bacteriana, bem como a respeito do uso de plantas diretamente ligadas ao gênero Myracrodruon e a família Anacardieaceae para esta finalidade. Tal fator pode estar relacionado a baixa aplicabilidade de recursos financeiros direcionados ao setor de desenvolvimento inovação e ciência, mas por outro lado pode estar diretamente relacionado à falta de investigação a respeito das variáveis, o que abre uma margem para que estudos de desenvolvimento tecnológico sejam aplicados e demonstrem uma possibilidade de descobertas acerca dela, além de indicar produção para um consumo coletivo.

\section{Referências}

Batista, J. I. L., Barbosa, T. N., Rêgo, J. R. G., Rebouças, C. K. de O., Torres, T. M., Soares, K. M. de P., \& Bezerra, A. C. D. S. (2020). Contaminación microbiológica y parasitológica en lechuga (Lactuca sativa L.) comercializada en un municipio de la región semiárida brasileña. Research, Society and Development, 9(8), e196985592. https://doi.org/10.33448/rsd-v9i8.5592

Ce, C., Ep, S.-J., Lm, B., La, N., Tp, C., AK, M., Ka, R., Sm, C., Dd, A., Am, C., \& Fa, C. (2017). Anti-Leishmania activity of essential oil of Myracrodruon urundeuva (Engl.) Fr. All.: Composition, cytotoxity and possible mechanisms of action. Experimental Parasitology, 175, 59-67. https://doi.org/10.1016/J.EXPPARA.2017.02.012

da Silva, M. O., \& Aquino, S. (2018). Resistência aos antimicrobianos: uma revisão dos desafios na busca por novas alternativas de tratamento. Revista de Epidemiologia e Controle de Infecção, 8(4), 472-482. https://doi.org/10.17058/RECI.V8I4.11580

Sousa, D, D \& Silveira, J. A. (2018). Biodiversidade Na Escola: Uma Perspectiva De Ensino, Orientação E Difusão Ambiental. Revista Educação Ambiental Em Ação. https://revistaea.org/artigo.php?idartigo=3417

do Amaral, A. L., Morés, N., \& Junior, W. B. (n.d.). Comunicado Técnico Fatores Associados À Patologia Do Parto E Do Puerpério Na Fêmea Suína. http://www.cnpsa.embrapa.br/

Domingos, F. R., \& Silva, M. A. P. da. (2020). Uso, conhecimento e conservação de Myracrodruon urundeuva: uma revisão sistemática. Research, Society and Development, 9(11), e2329118851. https://doi.org/10.33448/rsd-v9i11.8851

Filipini, G. da S., \& Silva, G. da. (2019). Desenvolvimento de embalagens biodegradáveis ativas a partir de polímeros e extrato natural de jambolão. http://repositorio.furg.br/handle/1/8384

Goes, V. N., Palmeira, J. T., Moura, A. B. R., Andrade, M. A., Cavalcanti, R. B. de M. S., Gomes, L. L., Lima, F. de O., Sátyro, M. A. da S. A., Oliveira-Filho, A. A. de, Anjos, R. M. dos, Figueiredo, C. H. M. da C., \& Alves, M. A. S. G. (2020). Potencial fitoterápico do Chenopodium Ambrosioides L. na Odontologia. Research, Society and Development, 9(7), e818974983. https://doi.org/10.33448/rsd-v9i7.4983

GS, V., MA, B., \& FJ, M. (2003). Analgesic and antiinflammatory effects of chalcones isolated from Myracrodruon urundeuva allemão. Phytomedicine: International Journal of Phytotherapy and Phytopharmacology, 10(2-3), 189-195. https://doi.org/10.1078/094471103321659924

Hasenclever, L., Paranhos, J., Costa, C. R., Cunha, G., \& Vieira, D. (2017). A indústria de fitoterápicos brasileira: desafios e oportunidades. Ciência \& Saúde Coletiva, 22(8), 2559-2569. https://doi.org/10.1590/1413-81232017228.29422016

Indicadores mundiais relativos à propriedade intelectual: depósitos de pedidos de patente. (n.d.).

Júnior, P. S. S., Everton, G. O., Rosa, P. V. S., Souza, L. dos S., Conceição, F. O. V. de A., Soares, L. B. da C., Farias, W. K. dos S., Souza, L. dos S., Batista, C. L. C., Pinheiro, F. S., Neto, A. P. de A., \& Filho, V. E. M. (2020). Atividade larvicida do óleo essencial de Alpinia zerumbetfrente as larvas do mosquito Aedes aegypti. Research, Society and Development, 9(8), e194985578. https://doi.org/10.33448/rsd-v9i8.5578

Klein, T., Longhini, B., M., \& de Ciências, R. (2009). Fitoterápicos: um mercado promissor. Journal of Basic and Applied Pharmaceutical Sciences Rev Ciênc Farm Básica Apl, 30(3), 241-248.

L, K., P, K., O, L., \& P, N. (2019). Plant-Derived Products as Antibacterial and Antifungal Agents in Human Health Care. Current Medicinal Chemistry, 26(29), 5501-5541. https://doi.org/10.2174/0929867325666180831144344

Manuel, L., Bechel, A., Noormahomed, E. V., Hlashwayo, D. F., \& Madureira, M. do C. (2020). Ethnobotanical study of plants used by the traditional healers to treat malaria in Mogovolas district, northern Mozambique. Heliyon, 6(12), e05746. https://doi.org/10.1016/J.HELIYON.2020.E05746

Moraes, A. L., Araújo, N. G. P., \& Braga, T. de L. (2016). Automedicação: Revisando A Literatura Sobre A Resistencia Bacteriana Aos Antibioticos. Undefined.

Moraes, J. S., Santos, D. L., Fecury, A. A., Dendasck, C. V., Dias, C. A. G. de M., Pinheiro, M. da C. N., Souza, K. O. da, Silva, I. R. da, \& Oliveira, E. de. (2020). O uso da planta Cissus Verticillata (Insulina) no tratamento do Diabetes Mellitus, em uma comunidade costeira do Pará, Amazônia, Brasil. Research, Society and Development, 9(7), e443974273. https://doi.org/10.33448/rsd-v9i7.4273

Mota, Ê. B. F. da. (2019). Atuação de extratos naturais com efeito antimicrobiano sobre a conservação de pães do tipo integral. https://doi.org/10.11606/D.6.2019.TDE-10102018-081024 
Research, Society and Development, v. 10, n. 11, e138101119505, 2021

(CC BY 4.0) | ISSN 2525-3409 | DOI: http://dx.doi.org/10.33448/rsd-v10i11.19505

Moura, M. M. V. de, http://lattes.cnpq.br/4775892571714791, \& http://lattes.cnpq.br/4775892571714791. (2020). Atividade fotoprotetora de extratos vegetais: uma revisão da literatura. https://repositorio.ufpb.br/jspui/handle/123456789/17763

Novaes de Moraes, K., \& Ursula Gonzales Barron Vasco Cadavez Fabiano Alves de Oliveira Bragança, D. (2020). Modelação da Sobrevivência de Staphylococcus aureus em Bifes Revestidos com Extrato Oleoso de Sementes de Urucum (Bixa orellana L.) Orientada por.

Oliveira, A. K. M. de, Pina, J. C., Pereira, S. R., Bono, J. A. M., Matias, R., Pires, F. de F., \& Assis, T. E. de. (2020). Effect of basalt rock powder associated with different substrates on the initial development of aroeira seedlings (Myracrodruon urundeuva). Research, Society and Development, 9(12), e5591210790. https://doi.org/10.33448/rsd-v9i12.10790

PA, S., SD, D., \& J, S. (2018). A Review on Plant Antimicrobials of Past Decade. Current Topics in Medicinal Chemistry, 18(10), 812-833. https://doi.org/10.2174/1568026618666180516123229

Report on the Burden of Endemic Health Care-Associated Infection Worldwide Clean Care is Safer Care. (2011). www.who.int

Ribeiro Teixeira, A., Flávia Costa Figueiredo, A., \& Ferreira França, R. (2019). Resistência Bacteriana Relacionada Ao Uso Indiscriminado De Antibióticos. Revista Saúde Em Foco, 11, 853-875.

S, T., S, W., W, R., K, S., MA, B., A, P., AH, S., \& MA, R. (2019). A comprehensive review of the antibacterial, antifungal and antiviral potential of essential oils and their chemical constituents against drug-resistant microbial pathogens. Microbial Pathogenesis, 134. https://doi.org/10.1016/J.MICPATH.2019.103580

SA, Z., E, B., MD, L., M, R., A, P., \& M, S. (2017). Plant phenolics and terpenoids as adjuvants of antibacterial and antifungal drugs. Phytomedicine: International Journal of Phytotherapy and Phytopharmacology, 37, 27-48. https://doi.org/10.1016/J.PHYMED.2017.10.018

Santos, A. L. dos, Santos, D. O., Freitas, C. C. de, Ferreira, B. L. A., Afonso, I. F., Rodrigues, C. R., \& Castro, H. C. (2007). Staphylococcus aureus: visitando uma cepa de importância hospitalar. Jornal Brasileiro de Patologia e Medicina Laboratorial, 43(6), 413-423. https://doi.org/10.1590/S167624442007000600005

Saraiva Filho, D. E., Sousa, J. B. de, Santos, H. S. dos, \& Fontenelle, R. O. dos S. (2020). Compostos químicos isolados de extratos e óleos essenciais do gênero Zanthoxylum Linnaeus (Rutaceae) e seu potencial antimicrobiano. Hoehnea, 47, 2020. https://doi.org/10.1590/2236-8906-88/2019

Silva, S. M. P. de M. (2013). Potencial antibacteriano e modulador de resistência a drogas de extratos e constituintes de algas marinhas em staphylococcus aureus. Repositório Institucional Da UFPB. https://repositorio.ufpb.br/jspui/handle/tede/3653

Souza, R. P., Holanda, J. N. P. de, Sousa, L. R. B. de, Oliveira, D. de, Souza, D. C. P., \& Sousa, R. W. R. de. (2020). Desenvolvimento farmacotécnico e controle de qualidade de um gel crioterápico à base de extrato de gengibre, mentol e cafeína. Research, Society and Development, 9(6), e110963513. https://doi.org/10.33448/rsd-v9i6.3513 